\title{
Douglas Scott and Stuart McHardy, The Stones of the Ancestors: Unveiling the Mystery of Scotland's Standing Stones
}

\author{
Edinburgh: Luath Press Limited, 2020. Hardback 234 pp. ISBN: \\ 9781912147809. £25.00.
}

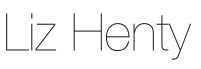

University of Wales Trinity Saint David lizhenty2@gmail.com

Douglas Scott is an archaeoastronomer whose opinions on cross-quarter solar orientations have been cited by Richard Bradley $(2011,87)$, who in the same volume included Scott's visualisation of the lunar orientation at the Pullyhour enclosure in Caithness, Scotland (Bradley 2011, 131). He has also published his findings on the solar lunar orientations of the Orkney-Cromarty and Clava Cairns (Scott 2016). Indeed, Scott has surveyed and photographed prehistoric monuments all over Scotland for 40 years. Stuart McHardy, meanwhile, is a self-described writer, musician, folklorist, storyteller and poet who has published several books on aspects of Scottish culture. I was intrigued to find out how their collaboration manifested in this new book on Scotland's standing stones and how they combined surveying, knowledge of the landscape, myth and oral traditions within their narrative.

The volume is aimed at the general public rather than academics, although it acknowledges the work of leading archaeologists who have written extensively on Scottish monuments. It is organised into two parts, firstly the authors' interpretations relating to the continuity of solar belief from the Neolithic to the Pictish period and secondly a selection of surveys by Scott of a wealth of different monuments. It concludes with an assessment by both authors of the reuse of the monuments in the Pictish period. The opening map shows that the locations studied are mainly in the north and east of Scotland and on the isles of Lewis and Orkney. The most southerly site is at Ballymeanoch in southwestern Argyll. The choice to use locations rather than chapter headings makes the work feel like a travel companion for those interested in touring sites of archaeoastronomical interest. At the beginning of the book there is a sparse glossary for readers unfamiliar with archaeoastronomical terms and a timeline which sets the monuments studied into their correct historical context. Again this is limited, because so few of the 
monuments have been accurately dated. Two simple pictorial guides which show the solar and lunar setting positions would have been better placed after the glossary in the prelims rather than at the end of the book.

The first section of Part 1, titled "The People of the Earth and Sky" (pp. 17-50), serves as a general introduction to the main premise that many monuments, petroglyphs and artefacts referenced the Sun in some way during the Neolithic - a practice which, according to the authors, gave way to solar/lunar references in the Bronze Age. They argue that solar continuity lasted until medieval times (p. 18), and betweentimes included the symbol stones of the Picts. This is a novel idea because generally the Picts form a discrete area of study, quite divorced from the earlier monument-building culture.

The "Monuments, Measurement and Myth" section argues somewhat emotionally for the usefulness of folklore, which is often discounted by archaeologists. In their eyes, the monuments were "essentially expressions of spiritual beliefs", based on the establishment of a "Neolithic calendar" (p. 22). Their alignments, first used in the building of small, chambered cairns, were then replicated in the complex sites such as The Ness of Brodgar and Calanais. While there are several references to Alexander Thom's surveying skills, they dismiss his ideas that the monument builders were skilled astronomers (p. 22). Rather, they are keen to make the case that the erection of these sites was a group activity which showed reverence for the dead.

The text in "The Monuments" section wanders off track occasionally, with titbits of speculation about fifteenth-century Scottish gravestones with representations of skulls and thighbones being a mnemonic of prehistoric burial rites (p. 23) or the belief in fairies being equated with the ancestors (p. 24). In the "Types of Monuments" section there is a bit of a mish-mash ranging from Gobekli Tepe in Anatolia, through developments in Brittany and Portugal, Stonehenge and Woodhenge in England, before honing in on the Scottish sites with some ideas on possible goddesses (the Westray Wife and the Ballachulish Goddess) thrown in for good measure. The poor copyediting of this section only adds to the confusion. The evidence is used to repeat the idea that the Neolithic solar calendar with its eight divisions, which was later replaced by the old agricultural calendar with its feast days of Imbolc, Beltane and so on, is a cultural marker throughout. There is less explanation of how the Moon's standstill cycles fit this narrative. Nevertheless, they insist that the relationship between the monuments to solar and lunar motions "does signify the application of a calendar" (p. 36). This is a contentious claim and calls to mind Alexander Thom's speculations (Thom 1967, 107-117) and those of Euan MacKie (1988), but they liken their version of the calendar to "a measurable approach to time" (p. 36) which gives it some plausibility as they associate the different time points to features of the pastoral seasons, such as the transhumance of cattle.

It is difficult to impose any sort of commonality when discussing such a variety of remains, and so the authors correctly point out that the actual building of them "reflects a unique and localised approach" (p. 34). However, in their wanderings round the various extant remains in Scotland they present opinions as facts, such as maintaining that there is a link between spirals incised into some rocks and the midwinter Sun (p. 30). The section on cupmarks is less flimsy: although there has been no definitive explanation 
of cupmarks they have generally been associated with the Moon, but here the authors suggest they could have marked sunsets and provide some stunning photographed examples (pp. 44-46). Overall, they argue that folklore - or "Geomythography", to use McHardy's term - is important because it perpetuates the ideas and beliefs of the monument communities and thereby helps us interpret both the monuments themselves and their locations (p. 39). Without a hint of irony they describe local storytelling as "the bedrock" (p. 41) of that culture.

Part 2, which concentrates on Scott's surveys of a range of different monuments, is more robust. He starts his journey in Orkney, famous for the Stenness and Brodgar stone circles, the Skara Brae village and the burial mound of Maeshowe. He covers Stenness (superimposed on the aerial photo are the stations of the Sun and the Moon), but other than giving latitude and longitude there are no dates, horizon altitudes or declinations. Also featured are the less well-known Odin stones, which no longer remain but are interestingly digitally added to a photo to show their position relative to the Stenness circle. One cannot deny the striking images but they all would have been improved with the superimposition of a North arrow, as it is quite difficult to assess the direction from which the photographs have been taken. Also photographed is the Barnhouse settlement, with its proposed solar or lunar orientations. Yet despite the authors' assertions it is difficult to swallow their support of MacKie's suggestion that "these cultures were presided over by some kind of astronomer priests" (p. 62); this is not that different from Thom's claim, which they dismissed earlier. There is less detail about the Ness of Brodgar complex with its mixture of different structures constructed on a site of over 2.5 ha, but it is perhaps ambitious for the authors to describe it as a complex of "20 or so temples" (p. 66).

No tour round Orkney would be complete without a visit to Maeshowe, and there is something of real interest in the authors' findings here. They reproduce Henry Dryden's 1866 plan, itself a redrawing of George Petrie's 1861 plan, and compare it with Charles Calder's 1928 plan. The latter lacked the original outer passage, though it is not clear when this was removed. This finding overturns the commonly held opinion that Maeshowe was aligned to the midwinter solstice sunset. With the earlier longer passage intact, only the sunlight coming from the sunset about 28 days before winter solstice could have reached about halfway along the passage. The authors claim that it was only after the outer passage was removed in the nineteenth century that the midwinter sunlight could reach the back wall of the central chamber, stating that this was not part of the original design (p. 81).

On the Scottish Isle of Lewis in the Outer Hebrides stands the unique cross-shaped monument of Calanais. The eastern row is directed towards a point where the Sun and the Moon rise about two weeks before the autumn equinox or after the spring equinox, while the western arm points to equinox sunset (p. 87). Although the centre line of the cross is directed on a north-south line there is some indication that the major lunar standstill Moon will set near the base of the central standing stone. Although there are some spectacular photographs, a detailed plan showing these alignments would have been more helpful.

The narrative then moves from Lewis to northeast Scotland, home to a distinct variety of monuments, the Recumbent Stone Circles (RSCs). However, the section starts with the 
site of Tom Nan Carragh, Strathspey, a formation of four standing stones, of which only three are erect today, on the western periphery of the main northeast region. There are numerous problems involved in imputing the intentionality of such stones despite the sunset photographs depicted. The most plausible alignments seem to be those to the Sun's cross-quarter setting positions (p. 93): photographs showing the line of the noon shadows might have helped here.

Of the 63 extant RSCs, this book only covers three: Sunhoney, Midmar Kirk and Tomnaverie. Their directions are remarkably similar, the recumbent stones all being aligned to the February and November cross-quarter solar setting positions. Unfortunately, there is no methodology to demonstrate why this is the case, and the fact that a high hill stands behind the Sunhoney arrangement whereas at Tomnaverie there are clear horizon views makes the findings seem at first counterintuitive. However, once the latitude and horizon altitude have been calculated for the azimuths of the recumbent arrangements and converted into declination, it can then be shown that although they are at a distance from one another and have different horizon altitudes, the calculated declinations are similar enough to form a conclusion about the cross-quarter sunsets. The lack of a clear explanation leaves the reader thinking that all the monuments in the group would have similar characteristics, whereas this is very far from being the case. For example, at the impressive Tyrebagger RSC, the recumbent is far enough south for the major standstill Moon to set over it at a position far distant from the cross-quarter position of the Sun (Henty 2015, 260-261).

Further south in Perthshire is Croft Moraig Stone Circle, which was re-examined by Richard Bradley in 2016, although his latest thoughts on it are not referenced. It is a site of considerable interest, and Bradley has confirmed that the most important of its features is "its relationship with a prominent mountain and the midsummer solstice" (Bradley and Nimura 2016, 148). The authors showcase 12 remarkable photos of this site, many of them featuring cup-marked stones. These often feature in Neolithic monuments in different parts of the world, and, as the authors point out here, their association with the movements of the Sun or the Moon is speculative (pp. 105, 115). There is some repetition of ideas already addressed in Part 1, but the collection of photos makes up for this. The authors try unsuccessfully to reference other cultures, such as the living traditions in Madagascar, to draw the conclusion that "cup and ring marks [...] were ritually used to contact the ancestors as the sun or moon rose out of or set into the Otherworld" (p. 120).

Argyll boasts a variety of monuments, and the selection chosen for the book includes the impressive Kintraw standing stone and its nearby cairns, cup- and ring-marked outcrops at Torbhlaren and Cairnbaan and the Temple Wood stone circles, stones of which also exhibit cupmarks and spirals. Despite the monuments' different forms the authors find a uniting link in their alignments to the solstices and lunar standstills. These are also reflected in the Nether Largie standing stones to the southeast of Temple Wood, carefully detailed on the accompanying plan (p. 148).

The further south the locations, the more complex is the rock art, particularly evidenced on the red sandstone walls at Ballochmyle, Ayrshire. As shown in the accompanying photo there are "cup and ring marks, rayed discs, snaking lines, spirals, crescent 
moon and [...] three deer" (p. 156). There is even the suggestion of a comet and a Bronze Age boat. By contrast, on the southern slopes of Cambret Hill in Galloway a large slab is completely covered by a large spiral, the centre of which connects to the centres of two small spirals forming a line which aligns to the midsummer sunrise and sunset, a pattern repeated at the carved bedrock at Drumtroddan, also in Galloway. The nearby Drumtroddan standing stones were also found to be aligned to the midsummer sunrise.

Moving forwards in time the authors examine whether there were continuities between the Neolithic lunisolar symbolism and the Pictish culture from the late Iron Age. Certainly, the Picts reused many of the stones, as evidenced by the Pictish carvings on the stones at Nether Corskie in Aberdeenshire; and the Pictish crescent and double disc shapes that are often found on cupmarked stones appear to symbolise the Sun and the Moon. The fact that many of the stones were embellished with Pictish drawings in situ does suggest continuity. Even if the cosmology changed, the earlier symbolism was not erased; rather, it seems to have complemented the new order.

Overall, the book is one of two halves which are not really reconciled by the very brief conclusion. It might have been predictable that speculative Geomythography does not sit well alongside fact-based archaeoastronomical surveys. Remove the speculation, bring in up-to-date references, include a detailed explanation of the methodology used, together with tables for cross-comparisons of the sites which had cross-quarter solar orientations and solstitial and standstill alignments, and then you would have a useful reference book. Although this did not seem to have been the publishers' aim, nevertheless this book has the potential to create a renewed interest in and a new following for these wonderful monuments and their relation to the skyscape.

\section{References}

Bradley, R., 2011. Stages and Screens: An Investigation of Four Henge Monuments in Northern and North-Eastern Scotland. Edinburgh: Society of Antiquaries of Scotland.

Bradley, R. and C. Nimura, 2016. The Use and Reuse of Stone Circles: Fieldwork at Five Scottish Monuments and its Implications. Oxford: Oxbow Books. https://doi.org/10.2307/j.ctv138wt9x

Henty, L. 2015. "Continuity or Change? A Microscopic Scale Analysis of Monuments and Ritual in Aberdeenshire". Journal of Skyscape Archaeology 1 (2): 243-275. https://doi.org/10.1558/jsa.v1i2.28258

MacKie, E., 1988. "Investigating the Prehistoric Solar Calendar". In Records in Stone: Papers in Memory of Alexander Thom, edited by C. L. N. Ruggles, 206-231. Cambridge: Cambridge University Press.

Scott, D., 2016. "The Solar Lunar Orientations of the Orkney-Cromarty and Clava Cairns". Journal of Skyscape Archaeology 1 (2): 45-66. https://doi.org/10.1558/jsa.v2i1.30036

Thom, A., 1967. Megalithic Sites in Britain. Oxford: Oxford University Press. 